\title{
Flexible Work Arrangements and Employee Work Attitudes: A Case-Based Inquiry of a Small Non-Profit Response to Crisis
}

\author{
Craig R. Seal \\ California State University, San Bernardino \\ Krystal Miguel Rawls \\ California State University, Dominguez Hills \\ Patrick T. Flaherty \\ California State University, San Bernardino \\ Di Fan \\ California State University, San Bernardino \\ Selina Sanchez \\ California State University, San Bernardino \\ Maria Garcia Guzman \\ California State University, San Bernardino
}

\begin{abstract}
We conducted an exploratory case-based study to examine the impact of adopting flexible work arrangements strategies in response to the Covid-19 pandemic on employee work attitudes for a small, regional non-profit. Our findings indicated the importance of managerial support and organizational commitment to moderate the relationship between flexible work arrangements and job satisfaction. We also explored the influence of technology efficacy and work-life balance on the model. Our paper provides support for the prior empirical and theoretical assumptions that flexible work arrangements can have a positive impact on employee work attitudes and may be an effective managerial tool in response to a crisis.
\end{abstract}

Keywords: flexible work arrangements, employee work attitudes, case-based inquiry

\section{INTRODUCTION}

Given the Covid-19 pandemic, our research team wanted to examine the impact of implementing flexible work arrangements (such as telecommuting and flextime policies) on employee work attitudes (such as job satisfaction and organizational commitment) for a small, regional non-profit. We also considered the influence of technology efficacy and work-life balance on the proposed relationships. This 
study was a qualitative, case-based research project to explore if prior empirical and conceptual models were still valid when initiating flexible work arrangements as a reaction to a crisis.

In non-crisis times, based on the literature, and as an organizational strategy, the initial conceptual model is that technology and perceived managerial support, moderates the relationship between work attitudes, work-life balance, and job performance when implementing flexible work arrangements (Boell et al., 2016; Julien et al., 2011; Ko et al., 2013; Townsend et al., 2016). Therefore, we wanted to confirm if those relationships still held when an organization was essentially forced to implement telework and alternative work arrangements without the usual planning and implementation phases, with a focus on a small, regional non-profit, that may not have the resources or expertise of larger for-profit firms to manage the transition.

The study provides a timely exemplar of the importance of managerial trust and organizational commitment toward organizational performance, supporting the potential positive impact of flexible work arrangements on employee work attitudes, even when implemented as a response to a crisis.

\section{Covid-19 Emergence and Impact}

The Covid-19 global pandemic emerged in December, 2019 (https:/www.cdc.gov/coronavirus/2019ncov/hcp/non-us-settings/overview/index.html) and at the time of this writing (May, 2021), there have been over 160 million confirmed cases and over 3 million deaths associated with the virus (https://covid19.who.int/). In addition to the direct human cost, organizations have engaged in one of the largest transformational changes in history, as governments, education, business, and society moved to an online delivery modality for products and services.

While no organization was spared, well-resourced organizations, or those that already had a strong online presence or online capacity, were likely to manage the transformative change better than others. But what about small, regional non-profits, with limited resources, reliant on off the shelf technology, and with a historical face-to-face, human interaction modality, as the cornerstone for their strategic value? Specifically, what would be the impact on employee job satisfaction and work life balance with a reactive, rather than proactive, adoption of flexible work arrangements?

\section{Small, Regional Non-Profit}

Our case-based research examined a small (12 employees, including the director and program managers), regional (one main administrative office and two satellite offices, covering a 20,000 squaremile service area) non-profit organization in southern California. Although there was a willingness to provide workplace flexibility prior to the pandemic, few took advantage of the opportunity and there were limited formalized policies and procedures regarding flexible work arrangements. Overall the organization focused on traditional face-to-face interactions and a set of standardized work hours, as the dominant employee work mode. At the time of our study, over 6 months had passed from the initial implementation of a fully online work model at the organization and our subsequent employee interviews.

\section{LITERATURE REVIEW}

The focus of the research is on the impact of flexible work arrangements (specifically telework and alternate work schedule policies and practices), technology efficacy, and perceived managerial support on employee work attitudes (specifically job satisfaction and organizational commitment) as well as work-life balance.

\section{Job Attitudes}

According to Chen and Fulmer (2018), "In the management literature, job attitudes represent the fundamental evaluation of one's job experience and are commonly conceptualized as consisting of two main attitudes, job satisfaction and organizational commitment" (p. 382). And in our case, we looked at both job satisfaction and organizational commitment. We define job satisfaction as the overall attitude and emotional evaluation (positive or negative) with compensation, promotional opportunities, co-worker 
relations, and job involvement (Chen \& Fulmer, 2018; Harrison et al., 2006; Locke, 1976). Whereas organizational commitment is defined as the personal alignment with organizational mission and values, and a willingness to persist with the organization, especially in the face of adversity (Chen \& Fulmer, 2018; Harrison et al., 2006; Meyer \& Allen, 1991). Based on prior literature, we would normally expect that the adoption of flexible work arrangements would have a positive impact on employee job attitudes.

\section{Flexible Work Arrangements}

Flexible work arrangements (or FWAs), also called family friendly work practices (FFWPs), comprise a list of various employee-focused work arrangements, including telecommuting and flextime (the focus of the current study), encompassing "adjustments to the timing, location or tasks of work" (Townsend et al., 2016, p. 2086). For our purposes, telecommuting is defined as working out of the office, in this case at home, using technology (such as the internet, email, phone, and web conferencing); whereas flextime is defined as an employee's authority to set her or his work schedule within the week (such as a 7am-3pm or $12-8 \mathrm{pm}$ schedule, or $9 \mathrm{am}-4 \mathrm{pm}$ and then $7-8 \mathrm{pm}$ ), while still maintaining a set level of overall hours (such as 40). Normally these are "intended to facilitate positive behaviors and attitudes toward work by improving work-life balance and employee well-being" (Ko et al., 2013, p. 546). According to Boell et al. (2016), there is a strong, positive correlation between FWAs (such as flexible schedule, location and hours) and employee work attitudes (including job satisfaction and organizational commitment). Even the "perceived availability" of FWAs, whether or not they are used by employees, are still "positively related" to job attitudes (Chen \& Fulmer, 2018, p. 386). However, what is the impact of these work arrangements as a reactionary tactic, rather than as a proactive strategy, in response to an organizational crisis? Do the relationship still hold?

\section{Managerial Support}

In terms of managerial support for flexible work arrangements, Allen (2001) defined a familysupportive supervisor as one which is, "sympathetic to employee's desires to seek balance between work and family and who engages in efforts to help the employee accommodate his or her work and family responsibilities" (p. 417), linking management support to family-friendly work practices. Julien, Somerville and Culp (2011), further "suggest that support of these work arrangements (compressed work week, flextime, and telework) at the immediate supervisor and senior management levels (as well as the composite measure of superiors support) is crucial" (p. 191) for the successful implementation of these arrangements. Ko et al. (2013) demonstrated the impact of managerial support on job satisfaction and perceived organizational performance, suggesting "that the main effects of managerial support and performanceoriented management on job satisfaction and perceived organizational performance are positive and significant" (p. 558). Finally, de Vries et al. (2019) found that the "maintenance of a high-quality superiorsubordinate relationship is particularly important" (p. 577) in supporting telework. Therefore, based on the literature, the initial conceptual model is that perceived managerial support, defined as perceived care and trust of the supervisor by the employees, moderates the relationship between flexible work arrangements and employee work attitudes.

\section{Work-Life Balance}

A key outcome of flexible work arrangements is the potential impact on work-life balance (Boell et al., 2016; Grant et al., 2013; Julien et al., 2011; Ko et al., 2013). For our purposes, we are defining work-life balance as the ability to better manage multiple responsibilities, including self and family care, as a result of flexible (or family friendly) work arrangements or practices. Our initial assumption is that the adoption of such practices will enhance employee work-life balance.

\section{Technology}

One other variable to consider is the access and efficacy to appropriate technology that facilitates successful telecommuting and flextime arrangements (Boell et al., 2016; Grant, et al., 2013). Taken together, in a normalized application, we would therefore expect that managerial support and technology 
efficacy to moderate the relationship between work attitudes and promote work-life balance. The question is whether these relationships hold in a non-normalized environment. Figure 1 provides a graphic of the research model.

\section{FIGURE 1 RESEARCH MODEL}

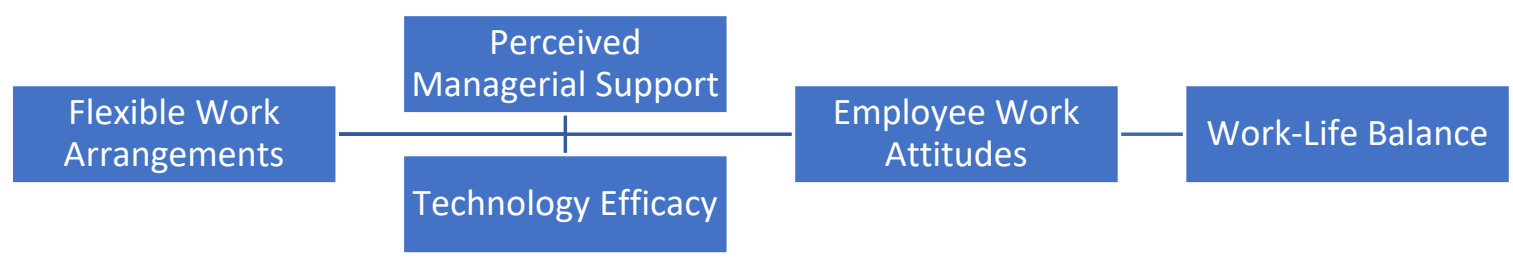

\section{METHODS}

The research team approached a small, regional non-profit as part of a broader consulting project, with the intent to provide value to the client and to develop a teaching case study for the team. In this study, with permission of the client leadership and the informed consent of the participants, the investigators examined the impact of flexible work arrangements, perceived managerial support, and technology efficacy on employee attitudes (job satisfaction and organizational commitment) and work-life balance.

Given the novelty of the issue and the small sample size, the study used qualitative research methods, including document analysis (review of the website, employee handbook, performance evaluation system, and organizational chart), narrative inquiry (that included the director and program manager, with a focus on current challenges and benefits of flexible work arrangement practices), and semi-structured interviews (that included all the employees, with a focus on work attitudes, perceived managerial support, and work life balance). Participation in the semi-structured interviews and narrative inquiry were confidential and participants were provided with an informed consent form. The final sample included the executive director and program manager (the 2 lead managers) for the narrative inquiry, and all 10 employees consented to participate in the semi-structured interviews, for a total of 12 participants. The population was predominantly female, with only the director and one employee identifying as male. The key research question was the impact of flexible work arrangements, technology, and managerial support on employee attitudes and work-life balance.

\section{RESULTS}

The key findings from the research supported the literature, with flexible work arrangements positively impacting job satisfaction in the case study, and organizational commitment, managerial support, and technology contributing to the positive relationship. In addition, the overall trust of the employees in their leadership and the strong identification with the organization mission highlighted the findings. However, work-life balance was still an issue of concern, as employees found little separation between work and personal life.

\section{Flexible Work Arrangements}

The organization implemented two flexible work arrangements in response to the Covid-19 pandemic: (1) telework (allowing employees to work from home); and (2) alternative work arrangements (providing flexibility on days/hours scheduled to work). Overall, the arrangements were positively received, with most 
employees hoping the flexibility continues (at least on a limited basis) once the pandemic crisis has passed. Specific comments included:

"Very flexible...Come to appreciate it. I love it." (Employee D)

"Maintain flexibility for family first is one of the hugest benefits." (Employee H)

"I love it, the work at home balance, puts their employees first, the work we do is very rewarding job...It has been helpful to be able to work remotely. Very beneficial." (Employee J)

While most preferred some level of onsite work (perhaps 1-2 days per week) and recommended more formalized core hours and formal office protocols, the hope is that some level of flexibility will be retained post pandemic. As predicted, the positive impact resulted from the perceived support of management in these work arrangements.

\section{Job Satisfaction}

We asked participants about their satisfaction with their job, pay and benefits, promotional opportunities, and co-worker relations. Overall, we found high levels of job satisfaction across participants, especially for job involvement and intrinsic motivation, with good feelings associated with the work itself, as well as with their co-worker relationships and extrinsic motivation. Some common themes included:

"Love what we do...see the fruits of the labor." (Employee E)

"Like that I'm able to work with them (volunteers) one-on-one, kind of have my own program, and a say in how I choose to help them." (Employee G)

"Like the flexibility, get to do a lot of different things...different challenges that arise that I am able to handle...very satisfied." (Employee I)

"Get along with co-workers really well. Part of the reason I stay." (Employee B)

"Satisfied, because everyone is friendly, but will let me know if doing something wrong, providing good positive feedback." (Employee F)

However, for pay and promotional opportunities, the reality of being a small non-profit led to lower satisfaction, as pay and advancement was limited. But employees understood these limitations, and still felt their job involvement, flexible benefits and development opportunities outweighed the pay and promotion restrictions. Some key thematic comments included:

“Know going into non-profits won’t make a lot of money.” (Employee B)

"Not always monetary, which makes up for it, like the flexibility. So many benefits, can't put a price on it." (Employee D)

"Working for non-profit, so pay not what it can be, but knew that when selected career wise." (Employee E)

"Not about the paycheck, all about the passion of loving what I do." (Employee H) 
"Had several promotions, as change in job roles, but not significant increases." (Employee B)

\author{
"Has (director) added responsibilities and pay." (Employee C) \\ "Always receiving continuous training opportunities, conference and workshops." \\ (Employee D)
}

"None, but that is ok, as can grow programs, and support of management." (Employee I)

The question for overall job satisfaction was the link to flexible work arrangements. In this case, it appeared that the staff already had high job satisfaction, especially in terms of job involvement and coworker relations, but that flexible work arrangements and perceived managerial support helped contribute to the positive evaluations.

\title{
Organizational Commitment
}

Organizational commitment was extremely high, and the main reason employees join and stay with the organization, with a strong alignment between the organization and employees' goals and values:

"Love the work and mission." (Employee A)

"Want to make a difference." (Employee C)

" $100 \%$ support...everyone working with (organization) believes it, put everything in whole heartedly, not just a paycheck...doesn't matter their role and work together to make it successful...go above and beyond our role." (Employee F)

"Having started as a volunteer I realized how important our work is, and my strong commitment, so invested in this job, it is the real deal, real life." (Employee J)

These high levels of commitment were also reflected in the flexible work arrangements (as outlined above) and managerial support (as outlined below). Based on the interviews, organizational commitment may serve as a moderator toward job satisfaction, rather than a separate dependent variable in the model, as initially expected.

\section{Managerial Support}

We asked participants to consider their overall satisfaction with management and perceived managerial support for the flexible work arrangement. Overall, perceived management support was extremely high across the interviews, in particular the trust between the employees and management. The strong trust between leader and followers helped to maintain the positive job satisfaction and strong organizational commitment, and facilitated the successful flexible work arrangements adoption:

"(Director) is very flexible, and does not micro-manage, does provide us the technology and does communicate if challenges or obstacles." (Employee A)

"Have an open relationship with boss, can openly express displease and be taken into consideration. Not micro-managed.” (Employee B)

"They have been amazing about it (FWAs) from the get-go. Bend over backwards for us, so we do the same." (Employee E) 
"If I express something I don't agree with, or ask why, they are understanding in helping out, explaining, or talking it out if necessary." (Employee F)

"Very satisfied...does an excellent job connecting and keeping us informed...(Director) trusts me, and don't want to let him down." (Employee I)

Thus, the support and trust of management, seemed to contribute to overall satisfaction and the success of the flexible work arrangements, indicating a possible moderator effect, as expected from the literature.

\section{Technology}

Additionally, we did ask about technology, which can impact the success or failure of flexible work arrangements, especially telework, and found most employees were comfortable with the systems available and felt competent to use them:

"Feel comfortable with technology." (Employee A)

"Lucky to have the tools and work remotely. Calling each other, MS teams, texting. Almost easier to connect directly." (Employee D)

Thus, technology did not significantly impact the relationship, as employees seemed to have the technology they needed to perform their jobs and were comfortable in using that technology.

\section{Work Life Balance}

Finally, one consistent theme, which was a bit of a surprise, was the negative impact on work life balance, with some employees having a hard time separating work from personal life:

"Personally, a struggle. Work, personal and school all blended." (Employee A)

"Overall, a positive for me (but) no physical separation of work and personal space." (Employee C)

"Affected me more emotionally...it is taking a toll." (Employee E)

"Been hard. Kind of balancing it all, with school, work, family, and personal. Overwhelming at times." (Employee F)

These findings on work-life balance may be more a result of the Covid-19 pandemic, and that in normal situations, where dependents are cared for, there are greater options for office use (or even alternative locations, such as a library or coffee shop), and appropriate planning (for home office set-ups) that may have ameliorated some of these concerns. But, taken at face value, work-life balance may be a negative moderator effect between flexible work arrangements and job satisfaction. As discussed by Gajendran and Harrison (2007), "If telecommuting were to enhance perceived autonomy and lower work-family conflict, this would, in turn, enhance job-related attitudes, improve performance, and reduce stress" (p. 1526).

Overall, the findings indicate the importance of managerial support, in particular trust, as well as organizational commitment (as an intervening variable) and technology adoption to support flexible work arrangements, while maintaining high levels of job satisfaction, as suggested by Baker, et al. (2007) and Grant et al. (2013). But work-life balance is still an issue that may hinder overall success, as indicated earlier. Thus, a revised model from the research findings is: 
FIGURE 2

\section{RESEARCH FINDINGS}

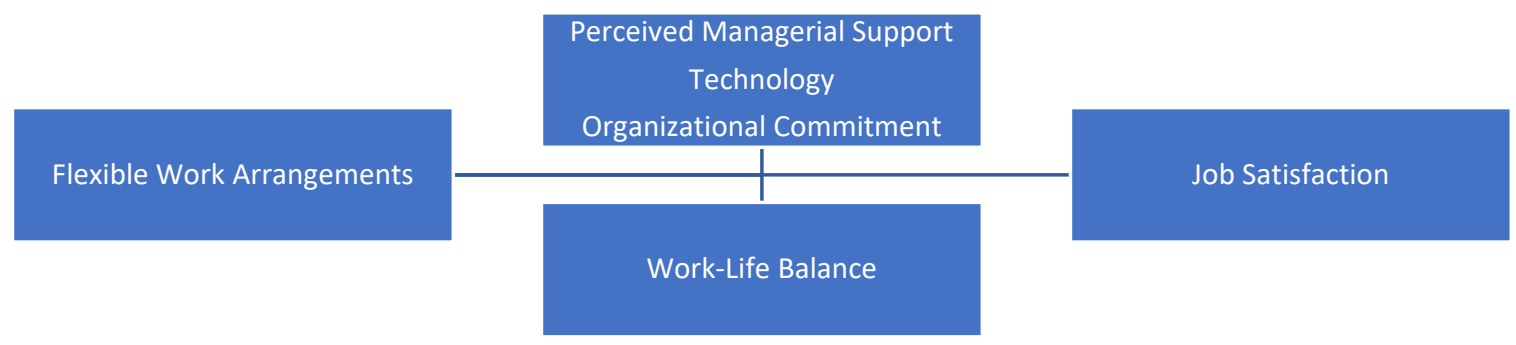

\section{CONCLUSION}

As the world of work continues to evolve and change, with the advent of increased technology and the need for greater flexibility and resiliency, the importance of perceived managerial support, in particular trust, is a key ingredient to the success of flexible work arrangements (FWAs) such as telecommuting and flextime at work. In addition, having strong organizational commitment, may also help to support the adoption of family friendly work practices. Therefore, the interaction of these variable is critically important to the success of FWAs. Of particular interest to the present study, is that these relationships persisted, despite the adoption of FWAs as a reaction to an organizational crisis (in this case the Covid-19 pandemic), rather than as a planned and phased in strategic human resource policy. But concerns persist, with the potential negative impact of FWAs on work-life balance, especially if other considerations, such as dependent care, office space, and internet connectivity are not adequately addressed.

\section{Future Considerations}

Although the study helped to confirm the importance of managerial trust and support as well as organizational commitment toward the successful adoption of flexible work arrangements and their potential positive impact on employee job satisfaction, there are several key limitations of the current study. First, the sample was based on a single, small, regional non-profit, which limits the generalizability of the results. Second, the sample was collected through semi-structured interviews, therefore there could be peer and management pressure and social desirability among participants that influenced their answers, as well as researcher bias on questions selected and interpretation of results. Third, the study was conducted 6months into the pandemic, so considerations of pre and post pandemic perceptions of job satisfaction and managerial support would be important, but were beyond the scope of the current study.

Given the results and limitations, next steps may be to see if the relationships hold in other organizations, including those larger in scale, those with a for-profit mission, and those with a different product or service model. In addition, the study did not address employee performance, which would help to verify if the perceived relationships emerge in more quantitative and qualitative changes in work outputs, beyond perceptions and attitudes. Finally, considering a longitudinal study, examining an organization before, during and after adopting FWAs, as well as how organizations change post-pandemic, and what online and hybrid workplace policies and procedures are retained is suggested.

Overall, the findings did help to draw attention to the important of managerial support, in particular trust, as well the potential paradoxical relationship between flexible work arrangements, work attitudes, and work-life balance. 


\section{REFERENCES}

Allen, T.D. (2001). Family-supportive work environments: The role of organizational perceptions. Journal of Vocational Behavior, 58, 414-435.

Baker, E., Avery, G.C., \& Crawford, J. (2007). Satisfaction and perceived productivity when professionals work from home. Research and Practice in Human Resource Management, 15(1), $37-62$.

Boell, S.K., Cecez-Kecmanovic, D., \& Campbell, J. (2016). Telework paradoxes and practices: The importance of the nature of work. New Technology, Work and Employment, 31(2), 114-131.

Chen, Y., \& Fulmer, I.S. (2018). Fine-tuning what we know about employees' experience with flexible work arrangements and their job attitudes: Flexible work arrangements. Human Resource Management, 57(1), 381-395.

de Vries, H., Tummers, L., \& Bekkers, V. (2019). The benefits of teleworking in the public sector: Reality or rhetoric? Review of Public Personnel Administration, 39(4) 570-593.

Gajendran, R.S., \& Harrison, D.A. (2007). The good, the bad, and the unknown about telecommuting: Meta-analysis of psychological mediators and individual consequences. Journal of Applied Psychology, 92(6), 1524-1541.

Grant, C.A., Wallace, L.M., \& Spurgeon, P.C. (2013). An exploration of the psychological factors affecting remote e-worker's job effectiveness, well-being and work-life balance. Employee Relations, 35(5), 527-546.

Harrison, D.A., Newman, D.A., \& Roth, P.L. (2006). How important are job attitudes? Meta-analytic comparisons of integrative behavioral outcomes and time sequences. Academy of Management Journal, 49, 305-325.

Julien, M., Somerville, K., \& Culp, N. (2011). Going beyond the work arrangement: The crucial role of supervisor support. Public Administration Quarterly, 35(2), 167-204.

Ko, J., Hur, S.U., \& Smith-Walter, A. (2013). Family-friendly work practices and job satisfaction and organizational performance: Moderating effects of managerial support and performance-oriented management. Public Personnel Management, 42(4), 545-565.

Locke, E.A. (1976). The nature and causes of job satisfaction. In M.D. Dunnette (Ed.), Handbook of industrial and organizational psychology (pp. 1297-1349). Palo Alto, CA: Consulting Psychologists Press.

Meyer, J.P., \& Allen, N.J. (1991). A three-component conceptualization of organizational commitment. Human Resource Management Review, 1, 61-89.

Townsend, K., McDonald, P., \& Cathcart, A. (2016). Managing flexible work arrangements in small notfor-profit firms. International Journal of Human Resource Management, 28(14), 2085-2107. 